\title{
Influencing Factors of Pacing Variations and Performance in a 44-Kilometer Mountain Trail Race
}

\author{
Alain Groslambert $1^{*}$, Bertrand Baron ${ }^{1,2}$, Théo Ouvrard1, Landry Desmoulins ${ }^{3}$,

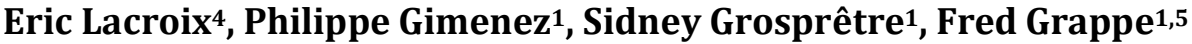

\author{
${ }^{1}$ Laboratoire C3S Culture, Sport Santé, Société, EA 4660, Université de Bourgogne Franche-Comté, Besançon, France \\ ${ }^{2}$ ESPACE-DEV, Université Montpellier, IRD, Université Antilles, Université Guyane, Université Réunion, Montpellier, France \\ ${ }^{3}$ Laboratoire de Simulation et Modélisation du Mouvement, Département de Kinésiologie, Université de Montréal, Montréal, \\ Canada \\ ${ }^{4}$ Service Universitaire des Activités Physiques et Sportives, Université de la Réunion, Saint Denis, France \\ ${ }^{5}$ Equipe Cycliste Groupama-FDJ, France \\ Email: *alain.groslambert@univ-fcomte.fr
}

How to cite this paper: Groslambert, A. Baron, B., Ouvrard, T., Desmoulins, L., Lacroix, E., Gimenez, P., Grosprêtre, S., \& Grappe, F. (2020). Influencing Factors of Pacing Variations and Performance in a 44-Kilometer Mountain Trail Race. $A d$ vances in Physical Education, 10, 81-96. https://doi.org/10.4236/ape.2020.102008

Received: November 12, 2019

Accepted: April 13, 2020

Published: April 16, 2020

Copyright $(2020$ by author(s) and Scientific Research Publishing Inc. This work is licensed under the Creative Commons Attribution International License (CC BY 4.0).

http://creativecommons.org/licenses/by/4.0/

\begin{abstract}
Objective: This study aimed to analyse the changes in the biomechanical and psychophysiological responses, and the body mass of trailers in a small-distance (44 km and $1520 \mathrm{~m}$ elevation gain) trail competition performed in tropical conditions. Methods: Ten trained trailers ( 8 men, 2 females; age: $42.0 \pm 5$ years, body mass: $65.57 \pm 5.4 \mathrm{~kg}$, height: $174.9 \pm 5.9 \mathrm{~cm} \mathrm{BMI:} 21.71 \pm 2.1$, Maximal Aerobic Speed (MAS): $16.6 \pm 2.1 \mathrm{~km} \cdot \mathrm{h}^{-1}$ ) volunteered to take part in the competition, comprising eight laps of $5.5 \mathrm{~km}$. At the end of each lap, the trailers had to stop for $10 \mathrm{~min}$ to perform tests measuring 1 ) the maximal horizontal force (F0), theoretical maximal running velocity (V0) and maximal power output $(\mathrm{PO})$ during a $30-\mathrm{m}$ sprint; 2 ) the vertical oscillations and maximal relative force during a 30-s treadmill submaximal run; 3 ) the perceived exertion and pleasure; and 4) body mass. The pacing, stride variations and heart rate were continuously recorded during the race. Results: The variations of PO $\left(\mathrm{W} \cdot \mathrm{kg}^{-1}\right)$ during the $30-\mathrm{m}$ sprint and perceived pleasure were significant ( $p=0.003$ and $p=0.02$, respectively) influencing factors of pacing. A significant decrease $(p<0.0001)$ was observed for the body mass between the first and last laps. Fraction of MAS and MAS were significantly $(p=$ 0.004 and $p=0.04$, respectively) related to the trail performance. Conclusions: Training programmes could be proposed that include the increase of MAS, fraction of MAS and lower limb PO. During the competition, it could be interesting to plan a drinking programme to avoid potential thermoregulatory impairment, as well as psychological strategies to increase plea-
\end{abstract}


sure.

\section{Keywords}

Running, Maximal Aerobic Speed, Self-Regulated Exercise, Perceived Pleasure, Power Output

\section{Introduction}

Trail running races, which are competitions in a natural environment with minimal paved or asphalt road (not exceeding $20 \%$ of the total course), are becoming one of the most popular disciplines in endurance running (Hoffman \& Wegelin, 2009). In March 2018, a new classification of races was proposed by the International Trail Running Association (ITRA, 2018), with seven categories (from XXS to XXL) based on the bonus (ITRA points), running distances (0 to $270 \mathrm{~km}$ and more) and winner's approximate time (1 to $17 \mathrm{~h}$ and more). In trail running, self-pacing has a major influence on performance (Millet, 2011a). It is well known that self-pacing exercise can be regulated from a complex protective system, including both somatosensory feedback and anticipatory mechanisms that maintain homeostasis and prevent major physiological disturbance (Coquart et al., 2012; Noakes, 2012) or motivational intensity changes (Marcora, 2008). Recently, Kerhervé et al. (2015) observed that, during a 106-km mountain trail competition with a total elevation gain and loss of $5870 \mathrm{~m}$, the trailers combined positive pacing strategies (speed decreased from the start until 70\%-90\% of the total event duration) with an increase of velocity in the last $10 \%$ of the event, and an increase in rating of perceived exertion (RPE) in the last $30 \%$ of the competition. Previous studies have also suggested that changes in the stride pattern (Degache et al., 2013; Morin et al., 2011), neuromuscular alterations and perceived exertion (Fourchet et al., 2012; Giandolini et al., 2016; Lopez et al., 2011) could explain these self-regulating mechanisms in trail running. However, to the best of our knowledge, the respective effects of these variables on pacing and performance during real trail competitions have yet to be determined.

It has been reported that hydration status could have a significant influence on self-pacing during trail running. While Stearns et al. (2009) found that dehydration is associated with decreases in runners' ability to evenly pace themselves during a competitive situation, Hue et al. (2014) claimed that high performance over a 6-day, $142-\mathrm{km}$ trail running race in tropical conditions was associated with increased loss in both total body water and body mass per hour. These contradictory results remain unclear and require further investigations.

Finally, the determinants of successful trailers have been extensively investigated in XL and XXL races, and the results revealed the significant influence of physiological (Millet et al., 2011b), psychological (Krouse et al., 2011) and anthropometric parameters (Hoffman et al., 2010). Balducci et al. (2017) also found that XL trail performance was significantly related to both the maximal aerobic 
speed (MAS) and fraction of MAS (\% MAS) used in competition. However, to the best of our knowledge, the influence of these parameters is not well documented in shorter distance trail competition, especially the " $\mathrm{S}$ " category of the ITRA rule. In addition, the psycho-physiological and biomechanical responses, the body mass changes, and their possible impact on the health of the trailers have never been investigated during a real trail running competition performed in hot and humid environment.

Therefore, the purpose of the present study was to analyse the changes of biomechanical, physical, perceptual responses and anthropometric characteristics in trailers during a $44-\mathrm{km}$ and $1520-\mathrm{m}$ elevation gain trail competition performed in tropical conditions. We seek to determine the following: 1) the effects of each of these parameters on pacing and 2) the variables influencing the trail performance. The hypotheses of the study are as follows: 1) pacing is related to changes in the stride characteristics, heart rate (HR), sprint capacities, running pattern, perceptual responses and body mass, and 2) trail performance in the "S" category is related to the MAS and \%MAS.

\section{Methods}

\subsection{Participants}

Ten trained trailers, having all previously participated at least in one trail of 60 $\mathrm{km}$, volunteered to take part in this experimental competition. Prior to participating in the event, each trailer provided written informed consent, and the study was conducted in accordance with the ethical principles of the Declaration of Helsinki (1984) and approved by the regional ethics committee. One week before the race, the trailers performed a maximal running graded test until exhaustion on a track (Leger \& Boucher, 1980) to determine their Maximal Aerobic Speed (MAS) and maximal HR. The anthropometric characteristics and trail performance of the trailers are presented in Table 1.

\subsection{Experimental Instrument}

The experimental protocol (Figure 1) was carried out during a $44.0 \mathrm{~km}$ mountain trail experimental competition (corresponding to the " $\mathrm{S}$ " category in the ITRA classification) with a total elevation gain and loss of $1520-\mathrm{m}$ during the Colorado Trail 2017 at Reunion Island in June. To investigate the pacing variations and maintain a high level of motivation during all the experimentation, the experimental protocol was designed like a real trail competition constituted by eight laps of $5.5 \mathrm{~km}$ with $1.9 \mathrm{~km}$ of hilly terrain, $1.6 \mathrm{~km}$ of uphill, and $2.0 \mathrm{~km}$ of downhill. The total elevation gain and loss was 190 -m per lap. The mean running time was controlled at each lap with a microchip and manual timekeeper. At the end of each lap, the trailers had to stop in a paddock for $10 \mathrm{~min}$ to perform a set of tests. This study was conducted according to the recommendations of the Declaration of Helsinki. The research plan was examined and approved by the Ethics Committee of the responsible Institutional Department (University of 
Table 1. Mean $\pm S D$ and extreme values (under brackets) of the subjects' anthropometrics, physical characteristics, and trail performance. The time spent each lap at the paddock $\left(8^{*} 10 \mathrm{~min}=80 \mathrm{~min}\right)$ has been subtracted from the running time.

\begin{tabular}{cc} 
Variables & (n = 10) \\
\hline Gender & 8 men; 2 females \\
Age (years) & $42.0 \pm 5[36-52]$ \\
Level in competition & 4 initiated, 5 experienced and 1 elite \\
ITRA points & $642.9 \pm 65[564-776]$ \\
Height (cm) & $174.9 \pm 5.9[167-185]$ \\
Body mass (kg) & $65.57 \pm 5.4[57-74]$ \\
Body mass index (BMI) & $21.71 \pm 2.1[20.22-25.65]$ \\
Maximal heart rate (bpm) & $179.33 \pm 10.87[167-188]$ \\
Maximal Aerobic Speed $\left(\mathrm{km} \cdot \mathrm{h}^{-1}\right)$ & $16.60 \pm 2.07[14.00-19.00]$ \\
Fraction of MAS (\%) used during the competition & $44.75 \pm 5.14[38.70-50.09]$ \\
Distance traveled during the competition (km) & $44.0 \pm 0$ \\
Number of laps & 8.0 \\
Running time (min) & $362 \pm 51[302-412]$ \\
Running velocity $\left(\mathrm{km} \cdot \mathrm{h}^{-1}\right.$ ) & $7.44 \pm 1.14[5.59-8.74]$ \\
Coefficient of variation between the slowest and fastest laps & $8 \pm 3[4-13]$ \\
\hline
\end{tabular}

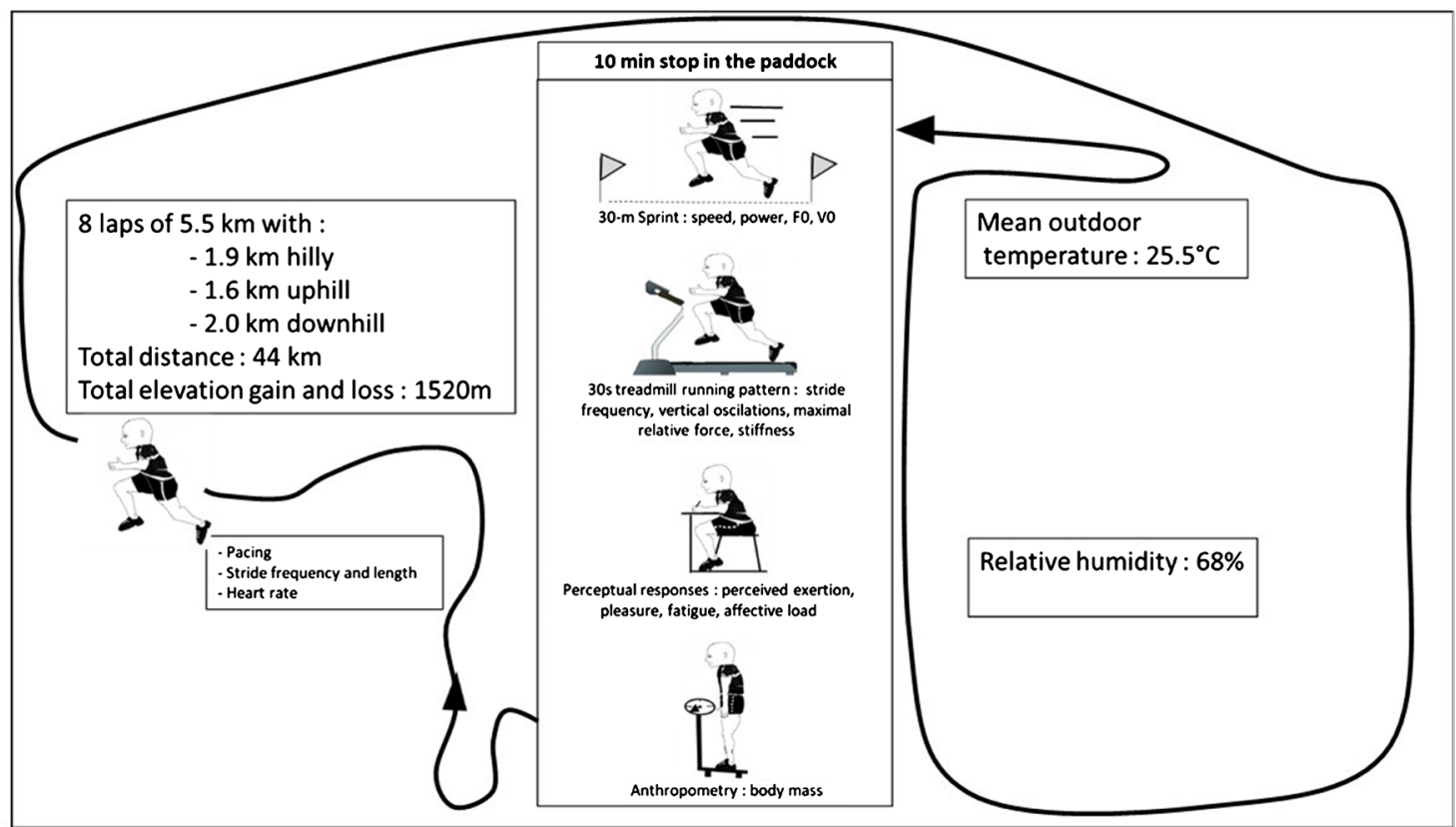

Figure 1. Schematic view of the experimental design.

\section{Franche-Comte).}

All the trailers started together at 6:00 am in tropical environmental conditions. The mean temperature was $25.5^{\circ} \mathrm{C}$, (extreme values, $20.1^{\circ} \mathrm{C}-30.5^{\circ} \mathrm{C} ; 68 \%$ relative humidity). Their pacing, stride variations (frequency and length) and 
HR were continuously recorded during the race by considering three gradients (uphill, downhill and hilly) using a GPS tracking watch with accelerometer and HR recording (Spartan Ultra, Suunto, Vantaa, Finland). Each watch was set to record one data point every $1 \mathrm{~s}$.

At the end of each lap, the trailers had to stop in a paddock for $10 \mathrm{~min}$ to record the following parameters:

\section{- Biomechanical parameters.}

o Their sprint capacities during a $30-\mathrm{m}$ sprint test on flat terrain with start stopping, where they were invited to give their best performance. To motivate the trailers, they were informed that their $30-\mathrm{m}$ sprint performances would be considered in the final ranking for the competition. In line with Romero-Franco et al. (Romero-Franco et al., 2017), the sprints were filmed with an iPhone ${ }^{\circledR} 7$ and analysed with the MySprint ${ }^{\circledR}$ application. The theoretical maximal horizontal force production was expressed in both absolute $(\mathrm{F} 0, \mathrm{~N})$ and relative $\left(\mathrm{F}_{\text {rel }} \mathrm{N} \cdot \mathrm{kg}^{-1}\right)$ values, and the theoretical maximal running velocity (V0) was extrapolated from the linear sprint force-velocity relationship with the application. The absolute and relative maximal power output, $\mathrm{PO}_{\max }(\mathrm{W})$ and $\mathrm{PO}_{\text {relmax }}\left(\mathrm{W} \cdot \mathrm{kg}^{-1}\right)$, respectively (determined as $\mathrm{PO}=\mathrm{F} 0 \times \mathrm{V0} / 4)$, mean running speed $\left(\mathrm{m} \cdot \mathrm{s}^{-1}\right)$ and maximal running speed $\left(\mathrm{m} \cdot \mathrm{s}^{-1}\right)$ were also calculated from the application; and

0 Their running pattern during a 30-s treadmill (Domyos ${ }^{\circledR} \mathrm{T} 520 \mathrm{~A}$ ) running test at $12 \mathrm{~km} \cdot \mathrm{h}^{-1}$ with 0 degrees of elevation. In accordance with Balsalobre-Fernández et al. (2017), the running was filmed with an iPhone ${ }^{\circledR} 7$, and the pattern was analysed with the Runmatic ${ }^{\circledR}$ application. The stride frequency $(\mathrm{Hz})$, vertical oscillations $(\mathrm{m})$, maximal relative force $(\mathrm{PC})$ and muscle stiffness $\left(\mathrm{kN} \cdot \mathrm{m}^{-1}\right)$ were recorded;

\section{- Perceptual parameters.}

o Their perceptual responses with the rating of fatigue (ROF, Micklewright, et al., 2017) and perceived exertion (CR10, Borg, 1990);

o Conforming to Baron et al. (2011), perceived pleasure was measured using a 0 - 10 rating scale, where 0 corresponded to "no pleasure" and 10 to "maximal pleasure". The affective load (AL) was calculated using the formula of Baron et al. (2011):

$$
\mathrm{AL}=\text { perceived exertion }- \text { perceived pleasure; }
$$

- Body mass (Tefal Premiss ${ }^{\circledR}$ weight scale), which was standardised (always the same clothes and without a backpack). After each set of tests, to avoid any influence of hypoglycaemia and hyperthermia on the development of fatigue (Nybo, 2008), the trailers were fed ad libitum with meals containing mainly carbohydrates, energy bars and drinks. The food and water intake during the trail were checked in real time by an experienced investigator to ensure that there was no major problem of energy intake during the experiment.

Due to the great number of trailers in the paddock simultaneously, it was not possible to perform all the tests for all the subjects within $10 \mathrm{~min}$. Consequently, 
we present the full results of laps 1, 3, 5, 7 and 8 . Indeed, the priority was conserving the competition's real conditions to maintain the highest possible motivation level.

\subsection{Statistical Analysis}

Data are reported as the means \pm standard deviations $(S D s)$. We performed stepwise linear regressions (XLStat software, Addinsoft, NY, USA) to examine the delta values of the variables from the independent predictors (28 variables presented in Table 2 and Table 3, including the stride characteristics, HR responses, sprint capacities, running pattern, perceptual responses and body mass) of mean pacing. In addition, as the results met the statistical assumptions for using parametric statistics (i.e. homogeneity of variance and normality of the sample distribution), a one-way analysis of variance (ANOVA) with repeated measures and Tukey post hoc test (Sigmastat 11.0, Jandel Scientific Software, CA, USA) were performed to determine possible changes between laps in the mean pacing, stride characteristics, HR responses, 30-m sprint capacities, running pattern on the treadmill, perceptual responses and body mass. Effect Sizes (ES) were calculated from extreme values using the formula of Hedges (1982). A complementary two-way (5 laps $\times 3$ gradients) repeated ANOVA and Tukey post hoc test were also performed for the pacing, HR and stride characteristics. The Pearson product-moment correlation coefficient was used to determine possible correlations between the trail performance (running velocity), MAS and fraction of MAS (\%) used during the competition. A $p$-value $<0.05$ indicated that the difference was statistically significant.

\section{Results}

The mean total running time was $362 \pm 51 \mathrm{~min}$, excluding the time spent at each lap at the paddock $\left(8^{*} 10 \mathrm{~min}=80 \mathrm{~min}\right)$. The mean velocity of participants over the total race was then $7.49 \pm 1.11 \mathrm{~km} \cdot \mathrm{h}^{-1}$. The mean fraction of MAS (\%) used during the competition was $44.75 \pm 5.14$.

Concerning the influencing factors of pacing, the stepwise linear regression analysis demonstrated that, among the 28 variables tested, the decrease of $\mathrm{PO}_{\text {relmax }}$ $\left(\mathrm{W} \cdot \mathrm{kg}^{-1}\right.$ ) (adjusted $r^{2}=0.58, t=6.619, p=0.003$ ) and perceived pleasure (adjusted $r^{2}=0.30, t=3.370, p=0.02$ ) between laps 1 and 8 were the independent influencing factors of mean pacing.

The statistical treatment revealed that there are significant changes in some variables during the trail running. Indeed, between the different laps (Figure 2 and Figure 3, Table 3), the one-way ANOVA revealed a significant increase in the mean pacing $(F=13.18, p<0.0001)$, perceived exertion $(F=25.34, p<$ $0.0001)$, affective load $(F=14.36, p<0.0001)$ and perceived fatigue $(F=24.94, p$ $<0.0001)$ and a significant decrease in the perceived pleasure $(F=3.59 ; p<$ $0.01)$, mean stride frequency $(F=6.51, p<0.005)$ and mean stride length $(F=$ $7.81, p<0.001)$, as well as body mass $(F=27.33, p<0.0001$, with $2.7 \%$ loss be- 
tween the first and last laps). In the 30 -m sprint, we observed a significant decrease in the mean speed $(F=7.58, p<0.0004)$, maximal speed $(F=7.75, p<$ $0.0004), \mathrm{PO}_{\text {relmax }}(F=4.65, p<0.006), \mathrm{PO}_{\text {max }}(F=5.53, p<0.002), \mathrm{F}_{\text {rel }}(F=4.23$, $p<0.001)$, and $\operatorname{Vo}(F=7.75, p<0.0005)$. No significant changes

Table 2. Mean $\pm S D$ of the pacing, stride characteristics and HR responses recorded during the 44-km trail competition.

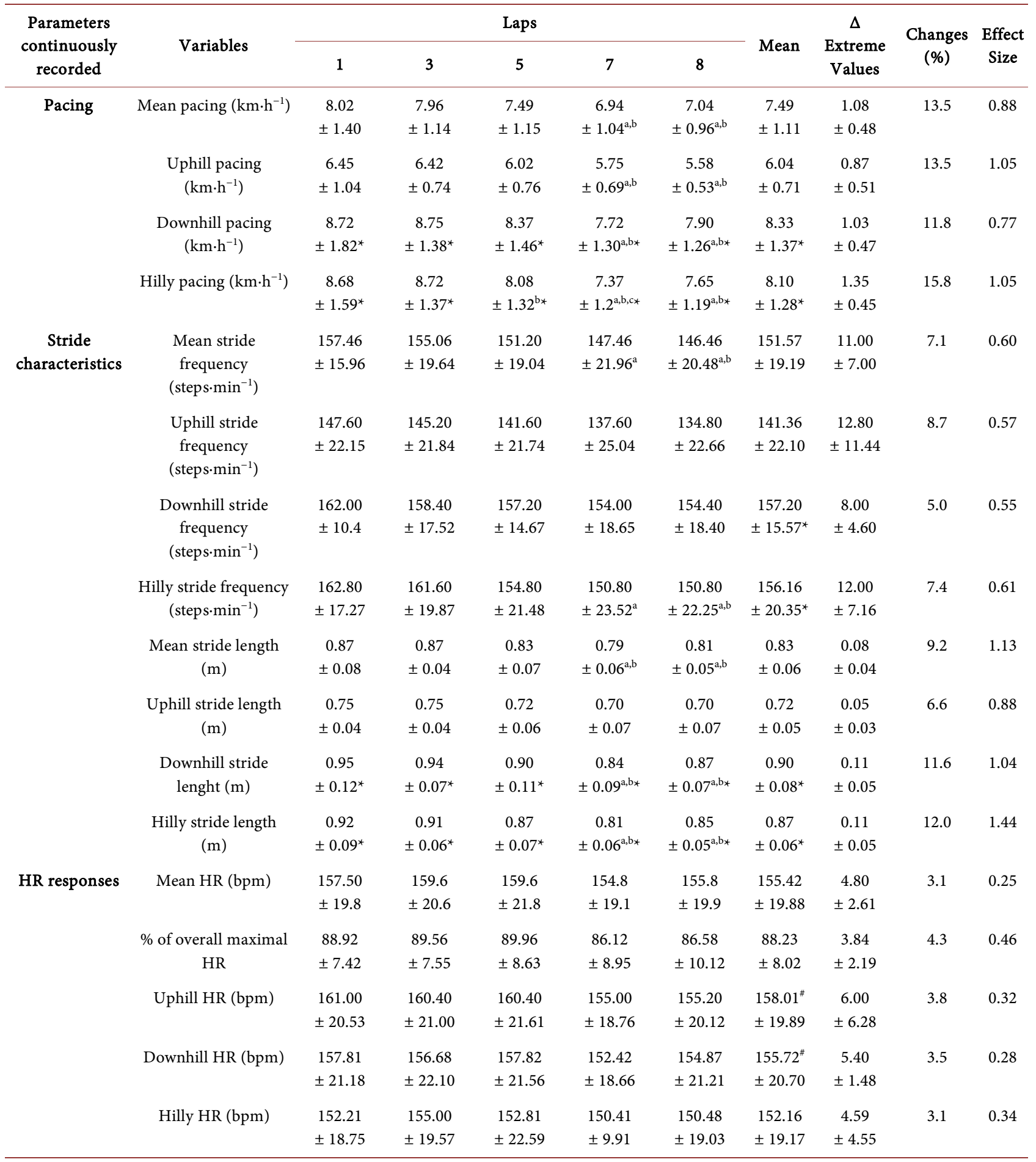

${ }^{\mathrm{a}} p<0.05$ compared with lap $1 ;{ }^{\mathrm{b}} p<0.05$ compared with lap $3 ;^{\mathrm{c}} p<0.05$ compared with lap 5 ; * compared with uphill, ${ }^{*} p<0.05$ compared with hilly gradient. 
Table 3. Mean $\pm S D$ of the sprint capacities, running pattern on the treadmill, perceptual responses, and body mass recorded at the end of each lap.

\begin{tabular}{|c|c|c|c|c|c|c|c|c|c|c|}
\hline \multirow{2}{*}{$\begin{array}{c}\text { Parameters } \\
\text { measured at the } \\
\text { end of each lap }\end{array}$} & \multirow{2}{*}{ Variables } & \multicolumn{5}{|c|}{ Laps } & \multirow{2}{*}{ Mean } & \multirow{2}{*}{$\begin{array}{c}\Delta \\
\text { Extreme } \\
\text { Values }\end{array}$} & \multirow{2}{*}{$\begin{array}{c}\text { Changes } \\
(\%)\end{array}$} & \multirow{2}{*}{$\begin{array}{r}\text { Effec } \\
\text { Size }\end{array}$} \\
\hline & & 1 & 3 & 5 & 7 & 8 & & & & \\
\hline \multirow[t]{7}{*}{$\begin{array}{l}\text { Sprint Capacities } \\
\text { in a } 30-\mathrm{m} \text { sprint }\end{array}$} & $\begin{array}{l}\text { Mean running speed } \\
\left(\mathrm{Km} \cdot \mathrm{h}^{-1}\right)\end{array}$ & $\begin{array}{r}20.54 \\
\pm 1.49\end{array}$ & $\begin{array}{r}19.71 \\
\pm 1.92\end{array}$ & $\begin{array}{r}18.03 \\
\pm 2.74\end{array}$ & $\begin{array}{c}16.13 \\
\pm 3.5^{\mathrm{a}, \mathrm{b}}\end{array}$ & $\begin{array}{l}16.95 \\
\pm 3.44^{\mathrm{a}, \mathrm{b}}\end{array}$ & $\begin{array}{r}18.11 \\
\pm 2.71\end{array}$ & $\begin{array}{c}4.41 \\
\pm 2.20\end{array}$ & 21.5 & 1.64 \\
\hline & $\begin{array}{l}\text { Maximal running speed } \\
\qquad\left(\mathrm{Km} \cdot \mathrm{h}^{-1}\right)\end{array}$ & $\begin{array}{r}22.92 \\
\pm 2.34\end{array}$ & $\begin{array}{r}21.46 \\
\pm 2.73\end{array}$ & $\begin{array}{r}19.20 \\
\pm 3.59^{\mathrm{a}}\end{array}$ & $\begin{array}{c}17.29 \\
\pm 4.3^{\mathrm{a}, \mathrm{b}}\end{array}$ & $\begin{array}{r}17.73 \\
\pm 4.62^{\mathrm{a}, \mathrm{b}}\end{array}$ & $\begin{array}{r}19.27 \\
\pm 3.74\end{array}$ & $\begin{array}{c}5.63 \\
\pm 2.43\end{array}$ & 24.6 & 1.65 \\
\hline & $\begin{array}{l}\text { Relative maximal power } \\
\text { output }\left(\mathrm{W} \cdot \mathrm{kg}^{-1}\right)\end{array}$ & $\begin{array}{r}18.33 \\
\pm 2.08\end{array}$ & $\begin{array}{r}17.39 \\
\pm 4.42\end{array}$ & $\begin{array}{r}15.25 \\
\pm 5.33\end{array}$ & $\begin{array}{l}11.80 \\
\pm 5.51^{\mathrm{a}, \mathrm{b}}\end{array}$ & $\begin{array}{r}12.80 \\
\pm 6.04^{\mathrm{a}}\end{array}$ & $\begin{array}{r}14.65 \\
\pm 4.55\end{array}$ & $\begin{array}{c}6.53 \\
\pm 2.70\end{array}$ & 35.7 & 1.57 \\
\hline & $\begin{array}{c}\text { Absolute maximal power } \\
\text { output }(\mathrm{W})\end{array}$ & $\begin{array}{r}1245.64 \\
\pm 190.88\end{array}$ & $\begin{array}{l}1167.16 \\
\pm 291.00\end{array}$ & $\begin{array}{r}1013.13 \\
\pm 321.29\end{array}$ & $\begin{array}{c}774.63 \\
\pm 380.61^{\mathrm{a}, \mathrm{b}}\end{array}$ & $\begin{array}{c}879.92 \\
\pm 387.93^{\mathrm{a}}\end{array}$ & $\begin{array}{r}1000.23 \\
\pm 279.73\end{array}$ & $\begin{array}{l}471.01 \\
\pm 222.3\end{array}$ & 37.9 & 1.57 \\
\hline & $\begin{array}{c}\text { Theoretical maximal absolute } \\
\text { horizontal force F0 }(\mathrm{N})\end{array}$ & $\begin{array}{r}771.05 \\
\pm 116.90\end{array}$ & $\begin{array}{l}749.47 \\
\pm 153.41\end{array}$ & $\begin{array}{r}713.59 \\
\pm 185.01\end{array}$ & $\begin{array}{r}603.10 \\
\pm 206.01\end{array}$ & $\begin{array}{r}648.48 \\
\pm 221.65\end{array}$ & $\begin{array}{c}693.01 \\
\pm 161.36\end{array}$ & $\begin{array}{r}167.95 \\
\pm 115.57\end{array}$ & 21.8 & 1.01 \\
\hline & $\begin{array}{l}\text { Theoretical maximal relative } \\
\text { horizontal force } \mathrm{F} 0\left(\mathrm{~N} \cdot \mathrm{kg}^{-1}\right)\end{array}$ & $\begin{array}{r}11.25 \\
\pm 1.59\end{array}$ & $\begin{array}{l}11.37 \\
\pm 1.77\end{array}$ & $\begin{array}{l}10.65 \\
\pm 2.65\end{array}$ & $\begin{aligned} & 9.04 \\
\pm & 2.94^{\mathrm{a}, \mathrm{b}}\end{aligned}$ & $\begin{array}{r}9.68 \\
\pm 2.91\end{array}$ & $\begin{array}{r}10.35 \\
\pm 1.88\end{array}$ & $\begin{array}{c}2.33 \\
\pm 2.58\end{array}$ & 20.5 & 0.95 \\
\hline & $\begin{array}{l}\text { Theoretical maximal running } \\
\text { velocity } \mathrm{V} 0\left(\mathrm{~m} \cdot \mathrm{s}^{-1}\right)\end{array}$ & $\begin{array}{c}6.55 \\
\pm 0.67\end{array}$ & $\begin{array}{c}6.19 \\
\pm 0.71\end{array}$ & $\begin{array}{c}5.66 \\
\pm 0.98\end{array}$ & $\begin{aligned} & 5.05 \\
\pm & 1.18^{\mathrm{a}, \mathrm{b}}\end{aligned}$ & $\begin{aligned} & 5.29 \\
\pm & 1.19^{\mathrm{a}}\end{aligned}$ & $\begin{array}{c}5.70 \\
\pm 0.98\end{array}$ & $\begin{array}{r}1.50 \\
\pm 0.46\end{array}$ & 23.0 & 1.56 \\
\hline \multirow[t]{4}{*}{$\begin{array}{l}\text { Running pattern } \\
\text { on the treadmill }\end{array}$} & Stride frequency $(\mathrm{Hz})$ & $\begin{array}{c}5.18 \\
\pm 1.45\end{array}$ & $\begin{array}{c}4.43 \\
\pm 1.25\end{array}$ & $\begin{array}{c}4.61 \\
\pm 1.36\end{array}$ & $\begin{array}{c}3.66 \\
\pm 1.37\end{array}$ & $\begin{array}{c}4.63 \\
\pm 1.16\end{array}$ & $\begin{array}{c}4.50 \\
\pm 1.32\end{array}$ & $\begin{array}{c}1.52 \\
\pm 1.38\end{array}$ & 29.5 & 1.13 \\
\hline & Vertical oscillations (m) & $\begin{array}{c}0.04 \\
\pm 0.02\end{array}$ & $\begin{array}{c}0.04 \\
\pm 0.01\end{array}$ & $\begin{array}{c}0.04 \\
\pm 0.02\end{array}$ & $\begin{array}{c}0.05 \\
\pm 0.01\end{array}$ & $\begin{array}{c}0.04 \\
\pm 0.01\end{array}$ & $\begin{array}{c}0.05 \\
\pm 0.01\end{array}$ & $\begin{array}{c}0.01 \\
\pm 0.01\end{array}$ & 20.0 & 1.00 \\
\hline & Maximal relative force (PC) & $\begin{array}{l}2.38 \\
\pm 0.1\end{array}$ & $\begin{array}{l}2.51 \\
\pm 0.2\end{array}$ & $\begin{array}{l}2.54 \\
\pm 0.2\end{array}$ & $\begin{array}{r}2.50 \\
\pm 0.2\end{array}$ & $\begin{array}{l}2.56 \\
\pm 0.2\end{array}$ & $\begin{array}{l}2.50 \\
\pm 0.1\end{array}$ & $\begin{array}{l}0.18 \\
\pm 01\end{array}$ & 15.0 & 1.14 \\
\hline & Stiffness $\left(\mathrm{kN} \cdot \mathrm{m}^{-1}\right)$ & $\begin{array}{c}52.40 \\
\pm 24.87\end{array}$ & $\begin{array}{c}47.99 \\
\pm 27.21\end{array}$ & $\begin{array}{c}53.26 \\
\pm 32.60\end{array}$ & $\begin{array}{c}27.29 \\
\pm 24.52\end{array}$ & $\begin{array}{c}49.05 \\
\pm 21.81\end{array}$ & $\begin{array}{c}46.00 \\
\pm 11.27\end{array}$ & $\begin{array}{c}25.97 \\
\pm 11.8\end{array}$ & 48.0 & 0.91 \\
\hline \multirow[t]{4}{*}{$\begin{array}{l}\text { Perceptual } \\
\text { responses }\end{array}$} & Perceived exertion & $\begin{array}{c}2.94 \\
\pm 1.33\end{array}$ & $\begin{array}{c}4.44 \\
\pm 1.67\end{array}$ & $\begin{array}{c}5.70 \\
\pm 1.25^{\mathrm{a}}\end{array}$ & $\begin{array}{c}7.00 \\
\pm 2.00^{\mathrm{a}, \mathrm{b}}\end{array}$ & $\begin{array}{c}7.20 \\
\pm 2.20^{\mathrm{a}, \mathrm{b}}\end{array}$ & $\begin{array}{c}5.44 \\
\pm 1.16\end{array}$ & $\begin{array}{c}4.26 \\
\pm 2.33\end{array}$ & 60.0 & 2.38 \\
\hline & Perceived pleasure & $\begin{array}{c}6.40 \\
\pm 3.13\end{array}$ & $\begin{array}{c}6.67 \\
\pm 2.37\end{array}$ & $\begin{array}{c}5.50 \\
\pm 3.06\end{array}$ & $\begin{aligned} & 5.00 \\
\pm & 3.32^{\mathrm{a}, \mathrm{b}}\end{aligned}$ & $\begin{array}{c}5.89 \\
\pm 2.85\end{array}$ & $\begin{array}{c}5.81 \\
\pm 2.80\end{array}$ & $\begin{array}{l}1.67 \\
\pm 6.3\end{array}$ & 24.9 & 0.58 \\
\hline & Affective load & $\begin{array}{l}-3.36 \\
\pm 3.45\end{array}$ & $\begin{array}{l}-2.06 \\
\pm 1.79\end{array}$ & $\begin{array}{c}0.20 \\
\pm 2.97^{\mathrm{a}}\end{array}$ & $\begin{aligned} & 2.00 \\
\pm & 3.69^{\mathrm{a}, \mathrm{b}}\end{aligned}$ & $\begin{array}{c}1.31 \\
\pm 3.70^{\mathrm{a}, \mathrm{b}}\end{array}$ & $\begin{array}{l}-0.30 \\
\pm 2.65\end{array}$ & $\begin{array}{c}5.36 \\
\pm 2.98\end{array}$ & 63.1 & 1.50 \\
\hline & Perceived fatigue & $\begin{array}{c}1.20 \\
\pm 1.39\end{array}$ & $\begin{array}{c}2.55 \\
\pm 1.87\end{array}$ & $\begin{array}{c}4.90 \\
\pm 1.37^{\mathrm{a}, \mathrm{b}}\end{array}$ & $\begin{aligned} & 5.30 \\
\pm & 2.21^{\mathrm{a}, \mathrm{b}}\end{aligned}$ & $\begin{array}{c}6.40 \\
\pm 2.45^{\mathrm{ab}}\end{array}$ & $\begin{array}{c}4.07 \\
\pm 1.47\end{array}$ & $\begin{array}{c}5.20 \\
\pm 2.70\end{array}$ & 82.0 & 2.61 \\
\hline Anthropometry & Body mass (kg) & $\begin{array}{r}64.86 \\
\pm 7.66\end{array}$ & $\begin{array}{l}63.97 \\
\pm 7.4\end{array}$ & $\begin{array}{r}63.51 \\
\pm 7.17\end{array}$ & $\begin{array}{l}63.27 \\
\pm 7.16\end{array}$ & $\begin{array}{c}63.12 \\
\pm 7.07^{\mathrm{a}}\end{array}$ & $\begin{array}{r}63.75 \\
\pm 7.29\end{array}$ & $\begin{array}{l}1.74 \\
\pm 0.9\end{array}$ & 2.7 & 0.24 \\
\hline
\end{tabular}

${ }^{\mathrm{a}} p<0.05$ compared with lap $1 ;{ }^{\mathrm{b}} p<0.05$ compared with lap 3.

$(p>0.05)$ were observed for the mean HR, percentage of maximal HR, F0 in the 30-m sprint, stride frequency, vertical oscillations, maximal relative force, or stiffness measured on the treadmill.

As presented in Table 3, for pacing, the two-way ANOVA revealed significant lap $(F=13.18, p<0.001)$ and gradient $(F=53.63, p<0.001)$ effects and interactions $(F=2.73, p<0.01)$. For the stride frequency, we also found significant lap $(F=6.51, p<0.005)$ and gradient $(F=19.44, p<0.001)$ effects, but no significant 

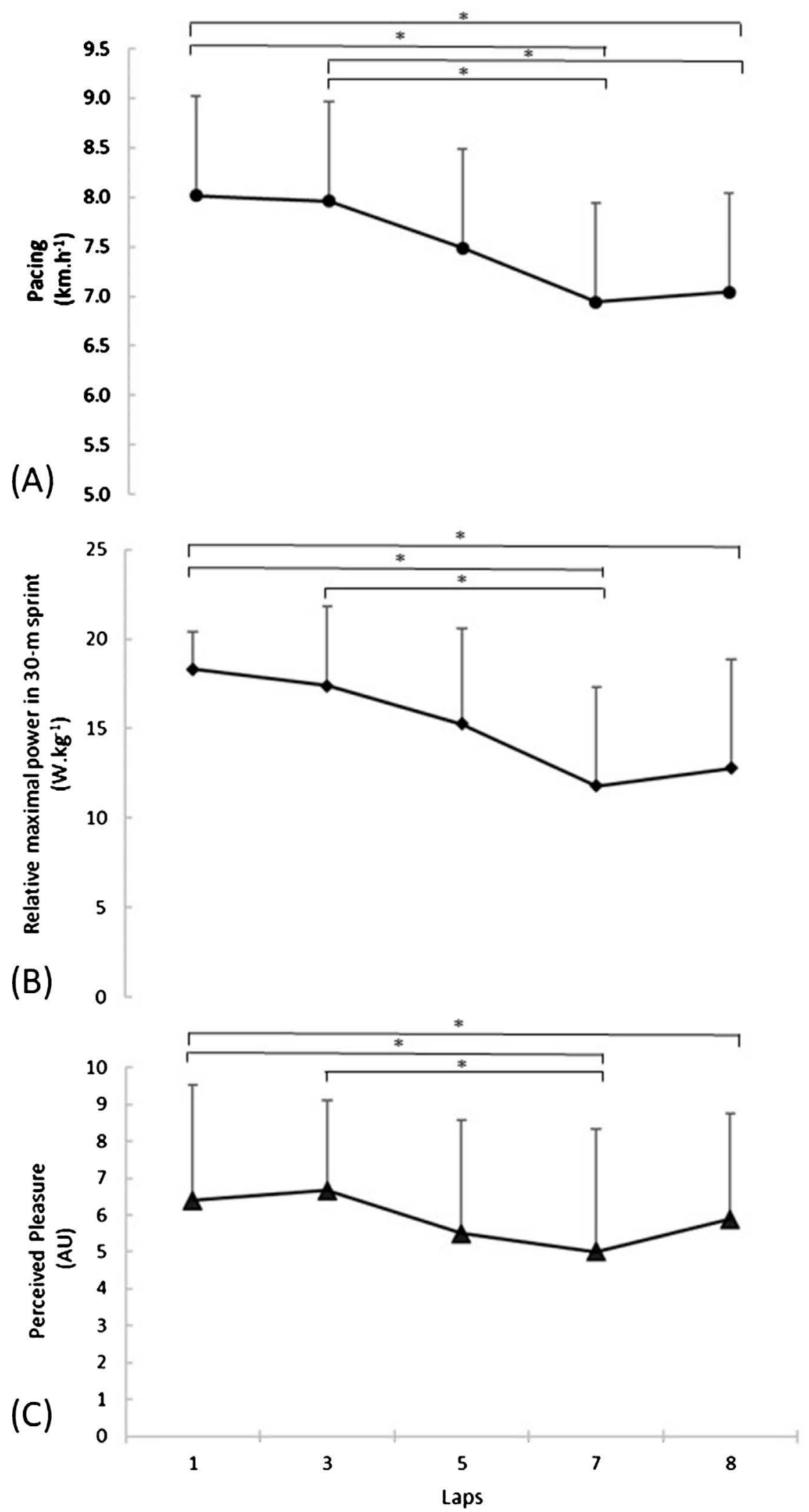

Figure 2. Evolution of pacing (panel A), relative maximal power output on a 30-m sprint (panel B) and perceived pleasure (panel C) during the trail running competition. ${ }^{\star} p<$ 0.05 . 


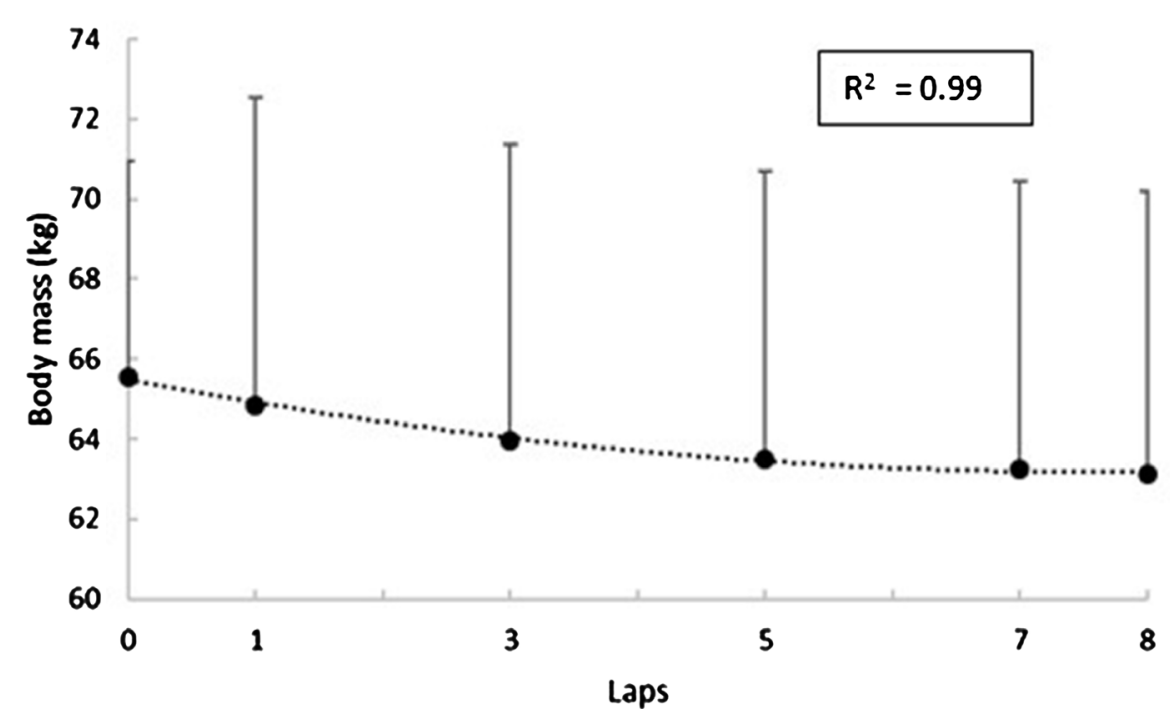

Figure 3. Evolution of the body mass before and during the trail running.

interactions ( $F=0.86, p=0.55)$ were observed. Concerning the stride length, we observed significant lap $(F=8.31, p<0.001)$ and gradient $(F=23.89, p<0.001)$ effects and interactions $(F=2.38, p<0.05)$. A significant $(F=16.58, p<0.001)$ gradient effect was found for HR, but neither a significant lap effect $(F=1.20, p$ $=0.34)$ nor interactions $(F=0.78, p=0.61)$ were observed.

It has been also found that there are variables significantly correlated to the running velocity. Indeed, a significant correlation was found between the mean running velocity and MAS $(r=0.63, p=0.04, t=2.34)$ and the fraction of MAS $(r=0.81 ; p=0.004 ; t=3.89)$.

In summary, the variations of $\mathrm{PO}\left(\mathrm{W} \cdot \mathrm{kg}^{-1}\right)$ during the $30-\mathrm{m}$ sprint and perceived pleasure are significant influencing factors of pacing. In addition, trail running in tropical environment decreases significantly the body mass between the first and last laps. Finally, the fraction of MAS and MAS are significantly related to the trail performance.

\section{Discussion}

The aim of the study was determining the respective effects of biomechanical, physical, and perceptual responses and body mass changes on pacing and the influencing variables on the trail performance.

The most important finding of the present study was that, among all the variables tested in the statistical treatment, $\mathrm{PO}_{\text {relmax }}$ and perceived pleasure were determined to be influencing factors for the overall pacing (Figure 4). Indeed, the variations (decrease from lap 1 to lap 7 and increase at lap 8) of the $\mathrm{PO}_{\text {relmax }}$ on 30-m sprint results from significant alterations of both velocity and force capabilities. The decrease of force capacities has been previously reported by Millet et al. (2011b) and confirmed by Saugy et al. (2013). Recently Giovanelli et al. (2017) also noted that the trailers characterised by greater maximal lower limb power were strongly related to smaller changes in running mechanics and pac- 
ing induced by fatigue. In line with these results, Vernillot et al. (2015) proposed incorporating specific downhill locomotion in the trailers' training programmes to improve the performance-related physiological and biomechanical parameters. It could be also suggested to trail coaches to propose training programmes including power lifting sessions to increase the lower limb power output. The variations of perceived pleasure (decrease from lap 1 to lap 7 and increase at lap 8 ) are the second significant independent variable influencing pacing. Baron et al. $(2011,2014)$ previously demonstrated that pleasure and positive emotions could balance perceived exertion and allow the athlete to sustain higher exercise intensity during the effort. Goal setting by fractioning the course in different stages (Tucker \& Noakes, 2009), self-talk (Mac Cormick, Meijen, \& Marcora, 2015), social support (Rochat et al., 2017) or an appetising meal during the race could be interesting ways of increasing pleasure.

Although not significantly correlated to pacing, other variables (the stride variations, speed sprint capacities, perceptual responses and body mass) change significantly during trail running. Indeed, the decreases of maximal speed sprint and $\mathrm{PO}_{\max }$, along with the increases in perceived exertion, affective load and fatigue, suggest that the trailers have self-regulated their running velocity to avoid early exhaustion occurring before the end of the event (Foster et al., 1994; Hettinga et al., 2006). Moreover, in competition conditions, as in the present study, the trailers keep enough reserves and motivation to be able to accelerate in the last lap to outdistance their opponents. The values of affective load could confirm the existence of an emotional reserve, as previously reported by Baron et al. (2011, 2014) and Abel \& Grappe (2016).

One interesting finding is the significant changes of the stride frequency and stride length observed in the different gradients, with a decrease in the running speed of $-1.3 \pm 0.5 \mathrm{~km} \cdot \mathrm{h}^{-1}(-15.8 \% \pm 3 \%)$ on hilly, $-1.1 \pm 0.4 \mathrm{~km} \cdot \mathrm{h}^{-1}(-11.8 \% \pm$ $3 \%)$ on downhill and $-0.8 \pm 0.5 \mathrm{~km} \cdot \mathrm{h}^{-1}(-13.5 \% \pm 7.3 \%)$ on uphill gradients. Kerhervé et al. (2015) observed also a running speed decrease during a 106-km mountain ultra-trail race, with $-2.9 \% \pm 2.1 \%$ on hilly, $-2.6 \% \pm 0.9 \%$ on downhill and $-1.3 \% \pm 0.8 \%$ on uphill gradients. The difference of percentages reported in this study could be explained by the fact that the authors used the mean running speed during the race, whereas in the present study, we determined the running speed decrease in each gradient from the delta of extreme values recorded between the slowest and fastest laps.

The significant curvilinear decrease of the body mass $(F=27.33 ; p<0.05$, $-2.7 \%$ between the first and last laps) is in accordance with Stearns et al. (2009) concerning dehydrated trailers performing a $12-\mathrm{km}$ running trail in the heat (with $-2.3 \%$ of body mass loss). One interesting point is that the trailers in our study were informed of their body mass loss at the end of each lap and strongly invited to drink and eat ad libitum. Despite these recommendations, the trailers continued to lose weight. This finding suggests that, in the environmental conditions of the present study, feeding ad libitum does not compensate for the body 
mass loss. This result has been previously reported by Stuempfle et al. (2011), who found that kilocalorie, fat, fluid and sodium consumption rates during an XL trail were significantly greater in finishers than they were in non-finishers. Therefore, we can reiterate Kenefick's suggestion (Kenefick, 2018) that when dehydration causes greater than $2 \%$ body mass loss in exercises with long duration ( $>90 \mathrm{~min}$ ), a tailored, programmed drinking strategy is required to avoid potential thermoregulatory and performance impairment.

One surprising result is the lack of significant alteration in the running pattern on the treadmill. Indeed, in the results of a 166- $\mathrm{km}$ mountain ultra-trail race, Morin et al. (2011) reported a significant increase in step frequency associated with reduced aerial times in trailers tested at $12 \mathrm{~km} \cdot \mathrm{h}^{-1}$ on a $7-\mathrm{m}$ pressure walkway. Degache et al. (2013) confirmed these observations for a 5-h running trail, where trailers were tested, as in the present study, on a treadmill at $12 \mathrm{~km} \cdot \mathrm{h}^{-1}$. Giovanelli et al. (2017) also observed a significant alteration of the running pattern, and especially, a decrease in aerial time after $4 \mathrm{~h} 30 \mathrm{~min}$ of running. This contradictory result remains unclear and requires further investigations.

Another surprising result is the lack of significant changes for the percentages of overall maximal HR, mean HR, and uphill, downhill and hilly HR between the laps. These results are in accordance with Kerhervé et al. (2015), who also reported no significant changes in HR before $70 \%$ of the total duration (around 12 h) of a 106-km running trail competition. In addition, our results seem to confirm that HR does not appear to be a significant predictor of pacing in the environmental conditions of our study.

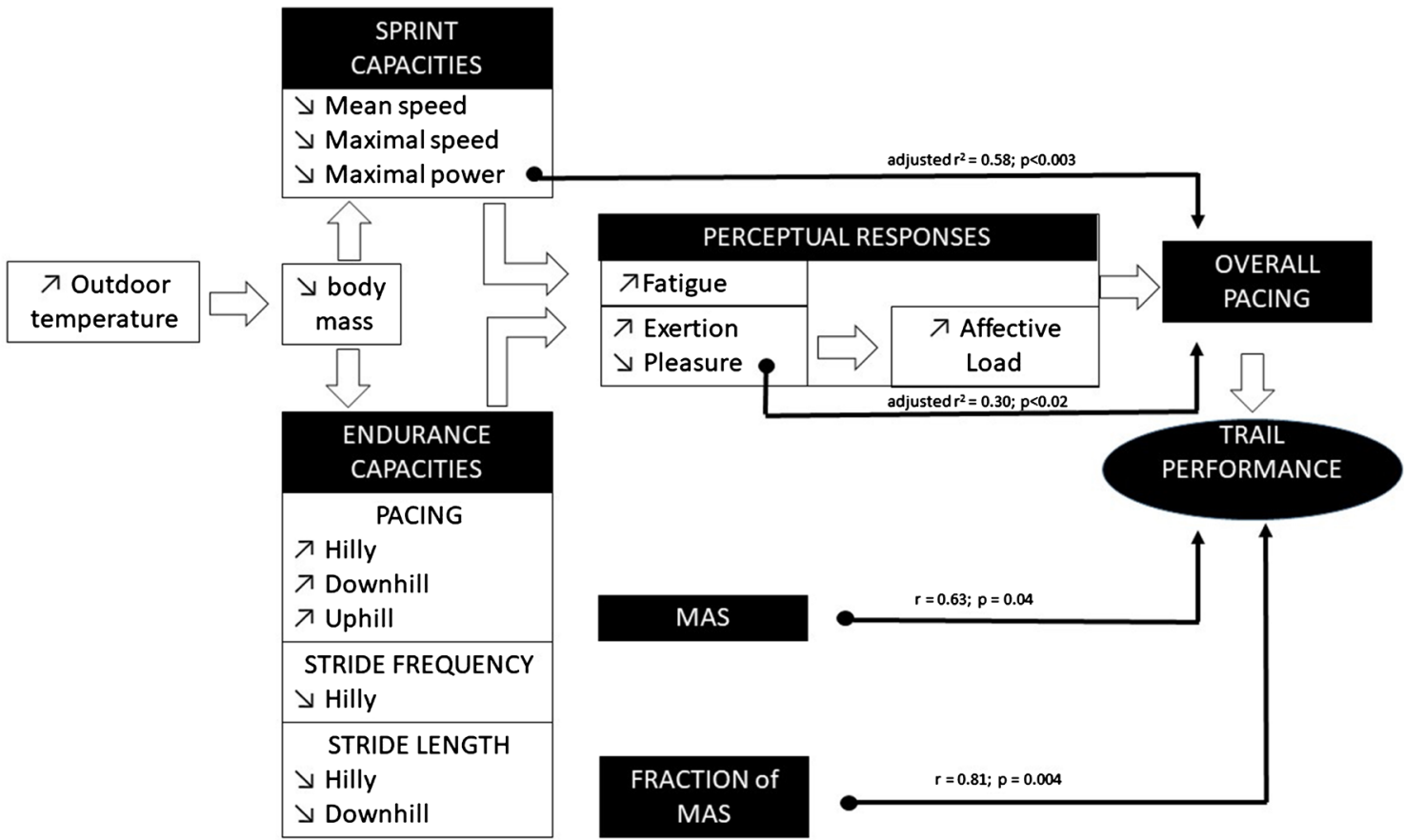

Figure 4. Holistic model of the biomechanical, physical and perceptual responses and the influencing factors of overall pacing and trail performance during an "S" mountain running trail race performed in a tropical environment. MAS: Maximal Aerobic Speed. 
Our study revealed that, among the different anthropometric and physical variables recorded before the race (i.e. body mass, BMI, MAS and fraction of MAS), only the fraction of MAS and MAS were significantly correlated to the running velocity. This finding is in line with Balducci et al. (2017), who observed a significant correlation between the MAS and running time $(r=-0.89, p<$ $0.001)$ in a $75-\mathrm{km}$ trail with a total positive elevation of $+3930 \mathrm{~m}$. This result is not surprising, considering that long-distance running performance depends on several factors, especially including the $\mathrm{VO}_{2 \max }$, fraction of $\mathrm{VO}_{2 \max }$ and energy cost of running (di Prampero et al., 1986, Wishnizer et al., 2013; Lazzer et al., 2014). Furthermore, our study confirms that the fraction of MAS used during the race is significantly related to the running trail performance, and the higher the fraction is, the better the performance will be. These findings have been previously reported by Balducci et al. (2017), suggesting that specific training sessions including MAS (e.g. interval training at MAS on the track) and fraction of MAS (endurance training under and near the anaerobic threshold) development are encouraged to increase the "S" trail running performance.

In this study, the main limitation may have been caused by the specific exercise induced in the recovery periods, when the trailers had to stop in the paddock for $10 \mathrm{~min}$ at the end of each lap. Although the stop in the paddock required moderate to intense exercise (30-s treadmill runs and 30-m sprint tests), it could have affected the trailers' perceptual, biomechanical and physiological responses. However, further investigations carried out on a large experimental sample, including a holistic approach with video recording of the running pattern and the perceptual responses (without any recovery period) are encouraged to confirm the results of the present study.

\section{Conclusion}

Our results revealed that the variations of $\mathrm{PO}_{\text {relmax }}$ and perceived pleasure are significant influencing factors for the overall pacing on a $44-\mathrm{km}$ mountain trail. In addition, fraction of MAS and MAS were significantly related to the trail running performance.

\section{Acknowledgments}

The authors would like to thank the trailers who take part in this study, Lucien Bois and the Racing Club of Saint Denis for their technical help in the organization of this experimental mountain trail race.

\section{Conflicts of Interest}

The authors declare no conflicts of interest regarding the publication of this paper.

\section{References}

Abel, A., \& Grappe, F. (2016). Case Study: Psycho-Physiological Parameters and Pacing 
Strategy Associated with a 6 Days 6 Nights Ultra-Endurance Event on Bike. Journal of Science and Cycling, 5, 1-2.

Balducci, P., Clémençon, M., Trama, R., Blache, Y., \& Hautier, C. (2017). Performance Factors in a Mountain Ultramarathon. International Journal of Sports Medicine, 38, 819-826. https://doi.org/10.1055/s-0043-112342

Balsalobre-Fernández, C., Agopyan, H., \& Morin, J. B. (2017). The Validity and Reliability of an iPhone App for Measuring Running Mechanics. Journal of Applied Biomechanics, 33, 1-16. https://doi.org/10.1123/jab.2016-0104

Baron, B., Moullan, F., Deruelle, F., \& Noakes, T. D. (2011). The Role of Emotions on Pacing Strategies and Performance in Middle and Long Duration Sport Events. British Journal of Sports Medicine, 45, 511-517. https://doi.org/10.1136/bjsm.2009.059964

Baron, B., Guilloux, B., Begue, M., \& Uriac, S. (2014). Emotional Responses during Repeated Sprint Intervals Performed on Hilly, Downhill and Uphill Surfaces. Journal of Sports Sciences, 33, 476-486. https://doi.org/10.1080/02640414.2014.947523

Borg, G. (1990). Psychophysical Scaling with Applications in Physical Work and the Perception of Exertion. Scandinavian Journal of Work and Environmental Health, 16, 55-58. https://doi.org/10.5271/sjweh.1815

Coquart, J. B., Eston, R. G., Noakes, T. D., Tourny-Chollet, C., L'hermette, M., Lemaître, F., \& Garcin, M. (2012). Estimated Time Limit: A Brief Review of a Perceptually Based Scale. Sports Medicine, 42, 845-855. https://doi.org/10.1007/BF03262298

Degache, F., Guex, K., Fourchet, F., Morin, J. B., Millet, G. P., Tomazin, K., \& Millet, G. Y. (2013). Changes in Running Mechanics and Spring-Mass Behaviour Induced by a 5-Hour Hilly Running Bout. Journal of Sports Sciences, 31, 299-304. https://doi.org/10.1080/02640414.2012.729136

di Prampero, P. E., Atchou, G., Bruckner, J. C., \& Moia, C. (1986). The Energetics of Endurance Running. European Journal of Applied Physiology, 55, 259-266. https://doi.org/10.1007/BF02343797

Foster, C., Schrager, M., Snyder, A. C., \& Thompson, N. N. (1994). Pacing Strategy and Athletic Performance. Sports Medicine, 17, 77-85. https://doi.org/10.2165/00007256-199417020-00001

Fourchet, F., Millet, G. P., Tomazin, K., Guex, K., Nosaka, K., Edouard, P., Degache, F., \& Millet, G. Y. (2012). Effects of a 5-h Hilly Running on Ankle Plantar and Dorsal Flexor Force and Fatigability. European Journal of Applied Physiology, 112, 2645-2652. https://doi.org/10.1007/s00421-011-2220-9

Giandolini, M., Horvais, N., Rossi, J., Millet, G. Y., Morin, J. B., \& Samozino, P. (2016). Acute and Delayed Peripheral and Central Neuromuscular Alterations Induced by a Short and Intense Downhill Trail Run. Scandinavian Journal of Medicine and Science in Sports, 26, 1321-1333. https://doi.org/10.1111/sms.12583

Giovanelli, N., Taboga, P., \& Lazzer, S. (2017). Changes in Running Mechanics during a 6-Hour Running Race. International Journal of Sports Physiology and Performance, 12, 642-647. https://doi.org/10.1123/ijspp.2016-0135

Hedges, L. V. (1982). Estimation of Effect Size from a Series of Independent Experiments. Psychological Bulletin, 92, 490-499. https://doi.org/10.1037/0033-2909.92.2.490

Helsinki (1984). Déclaration d'Helsinki et révisions successive. http://www.fondamentaux.org/?p=371

Hettinga, F. J., De Koning, J. J., Broersen, F. T., Van Geffen, P., \& Foster, C. (2006). Pacing Strategy and the Occurrence of Fatigue in 4000-m Cycling Time Trials. Medicine and Science in Sports Exercise, 38, 1484-1491. 
https://doi.org/10.1249/01.mss.0000228956.75344.91

Hoffman, M. D., \& Wegelin, J. A. (2009). The Western States 100-Mile Endurance Run: Participation and Performance Trends. Medicine and Science in Sports Exercise, 41, 2191-2198. https://doi.org/10.1249/MSS.0b013e3181a8d553

Hoffman, M. D., Lebus, D. K., Ganong, A. C., Casazza, G. A., \& Van Loan, M. (2010). Body Composition of 161-km Ultramarathoners. International Journal of Sports Medicine, 31, 106-109. https://doi.org/10.1055/s-0029-1241863

Hue, O., Henri, S., Baillot, M., Sinnapah, S., \& Uzel, A. P. (2014). Thermoregulation, Hydration and Performance over 6 Days of Trail Running in the Tropics. International Journal of Sports Medicine, 35, 906-911. https://doi.org/10.1055/s-0033-1361186

International Trail Running Association (ITRA) (2018). http://www.i-tra.org/page/259/Definition_of_trail-running.html

Kenefick, R. W. (2018). Drinking Strategies: Planned Drinking versus Drinking to Thirst. Sports Medicine, 48, 31-37. https://doi.org/10.1007/s40279-017-0844-6

Kerhervé, H. A., Millet, G. Y., \& Solomon, C. (2015). The Dynamics of Speed Selection and Psycho-Physiological Load during a Mountain Ultramarathon. PLoS ONE, 10, e0145482. https://doi.org/10.1371/journal.pone.0145482

Krouse, R. Z., Ransdell, L. B., Lucas, S. M., \& Pritchard, M. E. (2011). Motivation, Goal Orientation, Coaching, and Training Habits of Women Ultra Runners. Journal of Strength and Conditioning Research, 25, 2835-2842. https://doi.org/10.1097/01.JSC.0000395661.67282.81

Lazzer, S., Taboga, P., Salvadego, D., Rejc, E., Simunic, B., Narici, M. V., Buglione, A., Giovanelli, N., Antonutto, G., \& Grassi, B. (2014). Factors Affecting Metabolic Cost of Transport during a Multi-Stage Running Race. Journal of Experimental Biology, 217, 787-795. https://doi.org/10.1242/jeb.091645

Leger, L., \& Boucher, R. (1980). An Indirect Continuous Running Multistage Field Test: The Université de Montreal Track Test. Canadian Journal of Applied Sports Sciences, 5, 77-84.

Lopez, R. M., Casa, D. J., Jensen, K. A., DeMartini, J. K., Pagnotta, K. D., Ruiz, R. C., Roti, M. W., Stearns, R. L., Armstrong, L. E., \& Maresh, C. M. (2011). Examining the Influence of Hydration Status on Physiological Responses and Running Speed during Trail Running in the Heat with Controlled Exercise Intensity. Journal of Strength and Conditioning Research, 25, 2944-2954. https://doi.org/10.1519/JSC.0b013e318231a6c8

Mac Cormick, A., Meijen, C., \& Marcora, S. (2015). Psychological Determinants of Whole-Body Endurance Performance. Sports Medicine, 45, 997-1015. https://doi.org/10.1007/s40279-015-0319-6

Marcora, S. M. (2008). Do We Really Need a Central Governor to Explain Brain Regulation of Exercise Performance? European Journal of Applied Physiology, 104, 929-931. https://doi.org/10.1007/s00421-008-0818-3

Micklewright, D., St Clair Gibson, A., Gladwell, V., \& Al Salman, A. (2017). Development and Validity of the Rating-of-Fatigue Scale. Sports Medicine, 47, 2375-2393. https://doi.org/10.1007/s40279-017-0711-5

Millet, G. Y. (2011a). Can Neuromuscular Fatigue Explain Running Strategies and Performance in Ultra-Marathons? The Flush Model. Sports Medicine, 41, 489-506. https://doi.org/10.2165/11588760-000000000-00000

Millet, G. Y., Tomazin, K., Verges, S., Vincent, C., Bonnefoy, R., Boisson, R. C., Martin, V. et al. (2011b). Neuromuscular Consequences of an Extreme Mountain Ultra-Marathon. PLoS ONE, 6, e17059. https://doi.org/10.1371/journal.pone.0017059 
Morin, J. B., Tomazin, K., Edouard, P., \& Millet, G. Y. (2011). Changes in Running Mechanics and Spring-Mass Behavior Induced by a Mountain Ultra-Marathon Race. Journal of Biomechanics, 44, 1104-1107. https://doi.org/10.1016/j.jbiomech.2011.01.028

Noakes, T. D. (2012). Fatigue Is a Brain-Derived Emotion That Regulates the Exercise Behavior to Ensure the Protection of Whole Body Homeostasis. Frontiers of Physiology, 11, 1-13. https://doi.org/10.3389/fphys.2012.00082

Nybo, L. (2008). Hyperthermia and Fatigue. Journal of Applied Physiology, 104, 871-878. https://doi.org/10.1152/japplphysiol.00910.2007

Rochat, N., Hauw, D., Antonini Philippe, R., Crettaz von Roten, F., \& Ludovic Seifert, L. (2017). Comparison of Vitality States of Finishers and Withdrawers in Trail Running: An Enactive and Phenomenological Perspective. PLOS ONE, 12, e0173667. https://doi.org/10.1371/journal.pone.0173667

Romero-Franco, N., Jiménez-Reyes, P., Castaño-Zambudio, A., Capelo-Ramírez, F., Rodríguez-Juan, J. J., González-Hernández, J., \& Balsalobre-Fernández, C. (2017). Sprint Performance and Mechanical Outputs Computed with an iPhone App: Comparison with Existing Reference Methods. European Journal of Sport Sciences, 17, 386-392. https://doi.org/10.1080/17461391.2016.1249031

Saugy, J., Place, N., Millet, G. Y., Degache, F., Schena, F., \& Millet, G. P. (2013). Alterations of Neuromuscular Function after the World's Most Challenging Mountain Ultra-Marathon. PLoS ONE, 8, e65596. https://doi.org/10.1371/journal.pone.0065596

Stearns, R. L., Casa, D. J., Lopez, R. M., McDermott, B. P., Ganio, M. S., Decher, N. R., Maresh, C. M. et al. (2009). Influence of Hydration Status on Pacing during Trail Running in the Heat. Journal of Strength and Conditioning Research, 23, 2533-2541. https://doi.org/10.1519/JSC.0b013e3181b73c3f

Stuempfle, K. J., Hoffman, M. D., Weschler, L. B., Rogers, R. I., \& Tamara Hew-Butler, T. (2011). Race Diet of Finishers and Non-Finishers in a 100 Mile (161 km) Mountain Footrace. Journal of American College of Nutrition, 30, 529-535. https://doi.org/10.1080/07315724.2011.10719999

Tucker, R., \& Noakes, T. D. (2009). The Anticipatory Regulation of Performance: The Physiological Basis for Pacing Strategies and the Development of a Perception-Based Model for Exercise Performance. British Journal of Sports Medicine, 43, 392-400. https://doi.org/10.1136/bjsm.2008.050799

Vernillot, G., Savoldelli, A., Zignoli, A., Skafidas, S., Fornasiero, A., La Torre A., Schena, F. et al. (2015). Energy Cost and Kinematics of Level, Uphill and Downhill Running: Fatigue-Induced Changes after a Mountain Ultramarathon. Journal of Sports Sciences, 33, 1998-2005. https://doi.org/10.1080/02640414.2015.1022870

Wishnizer, R., Inbar, O., Klinman, E., \& Fink, G. (2013). Physiological Differences between Ethiopian and Caucasian Distance Runners and Their Effects on $10 \mathrm{~km}$ Running Performance. Advances in Physical Education, 3, 136-144.

https://doi.org/10.4236/ape.2013.33023 